\title{
Power as an ethical concern in the Global South's digital transformation
}

\author{
Power or empowerment?
}

Kutoma Wakunuma, De Montfort University, Gateway House, Centre for Computing and Social Responsibility (CCSR),

LE19BH, Leicester (kutoma@dmu.ac.uk), (1) orcid.org/0000-0002-8236-3221

The digitalization of the Global South, particularly with respect to African countries, is moving at a fast pace. This can be seen in the use of information and communications technology (ICT) in different domains such as healthcare, education, industry, entertainment, as well as in the provision of e-government services, to name just a few. Such digital progress is seen as positive and often presented as such in international development discussions, for example at the World Summit on the Information Society Forum 2019 on ICTs for achieving the United Nations' Sustainable Development Goals. Despite the positives, there are also negative aspects of digitalization, which have to be addressed in the form of ethical concerns. This paper discusses these concerns by specifically exploring the aspect of power in light of the digital transformation of the Global South. The discussion advanced in this paper is informed by a review of literature.

\section{Der ethische Aspekt der Macht in der digitalen Transformation des Globalen Südens \\ Macht oder Ermächtigung?}

Die Digitalisierung des Globalen Südens, insbesondere in afrikanischen Ländern, schreitet zügig voran. Dies zeigt sich am Einsatz von Informations- und Kommunikationstechnik (IKT) in verschiedenen Bereichen wie im Gesundheitswesen, in der Bildung, Industrie, Unterhaltung sowie bei der Bereitstellung von E-Government-Diensten. Dieser digitale Fortschritt wird positiv gesehen und oft als solcher in internationalen Entwicklungsgesprächen präsentiert, z. B. beim WSIS-Forum 2019 über IKT zur Erreichung der Ziele für nachhaltige Entwicklung der Vereinten Nationen. Neben dem Positiven gibt es aber auch negative Aspekte der Digitalisierung, die unter ethischen Gesichtspunkten betrachtet werden müssen. Auf Basis einer Literaturanalyse werden in diesem dem Artikel solche Erwägungen am Beispiel von Macht(verhältnissen) im Zuge der digitalen Transformation des globalen Südens diskutiert.

This is an article distributed under the terms of the Creative Commons Attribution License CCBY 4.0 (https://creativecommons.org/licenses/by/4.0/)

https://doi.org/10.14512/tatup.28.2.s29

Submitted: 10. 02.2019. Peer reviewed. Accepted: 15. 05.2019
Keywords: digitalization, power, Global South, ethical concerns, digital transformation

\section{Introduction}

The focus of this paper is on Africa's digital transformation where power as an ethical concern is discussed due to its concentration in a few actors' hands, such as US-based digital platform providers, Chinese technology investors, and national governments. Ethics is about morality and justice and this paper considers ethics from the point of view of Kant's deontology ethics (Darwell 2008) and virtue ethics (Hursthouse and Pettigrove 2018). Deontology ethics is rule or duty ethics; the expectation is that everyone conforms to the same rules and principles, therefore preventing harm, having respect for equality, rights, and justice. For instance, if it is agreed that infringement of privacy is morally wrong, it then becomes imperative for all stakeholders to respect privacy, either by putting in place policies that will ensure non-infringement of users' data or by being transparent about how data is used and managed for the benefit of all. Benefit for all ties into virtue ethics, which emphasizes virtues and moral character for the good of humanity. Therefore, applying the idea of virtue ethics means that whatever technological investments are done should not unduly lead to indebtedness or stifling of innovation for those in receipt of the investment, but rather help in propelling the recipients towards an equal footing.

Not applying these principles means that there are great risks and issues such as privacy and surveillance with power over Africa and its peoples being executed by the few mentioned actors. However, these actors are offering power to undertake positive expression and development through the use of digital platforms. To set the scene, the paper begins with an overview of the digital transformation of the Global South; this is followed by an 
exploration of power. The focus on power and what it means is discussed in the section on "conceptualizing power," after which the paper concludes.

\section{Digital Transformation}

Much has been said (ITU 2018; Wu et al. 2018; Gigler 2015) about the important role that information and communications technology (ICTs) play in development for the Global South. In this paper, the term 'Global South' is mainly alluding to countries in Africa. The importance of ICTs has led to a general consensus of their importance at the global level, re- nologies such as Twitter to enable their political participation. Social media outlets also allow users to use these platforms for entertainment, communication as well as exchange and share information on a number of issues ranging from the personal to the political.

Access to and use of digital technologies is often achieved through digital platforms, mostly originating in and owned by technology corporations from the Global North, namely the United States of America (U.S.). The digital transformation in the Global South has also been enabled by technology investments from countries with better economic standing such as China, which is investing substantially in many African countries. The fact that access and use are enabled by giant technol-

\section{Do the monopolies of (western) technology giants enable digital colonialism?}

sulting in support for their use and implementation in the Global South by international agencies such as the World Bank (2018) and the International Telecommunication Union (ITU) (2018; 2010). To further reinforce the importance of ICTs in the Global South, ICT strategies and policies have been developed in several countries of the Global South, including countries like Egypt, Rwanda, Kenya, and Zambia. The use of digital technologies can be seen in many areas, including health where e-health plays an increasingly important role. For example, in South Africa, ATM-like machines have been introduced to dispense medicines for people with chronic ailments such as HIV/AIDS. The e-pharmacy ATMs are a collaboration between Right to Care's subsidiary Right e-Pharmacy and Mach4, a German company supported by German and American development agencies GIZ (Deutsche Gesellschaft für Internationale Zusammenarbeit) and USAID (United States Agency for International Development) (Moyo 2017). Such digital technologies are believed to cut down on long waiting times, often experienced in more traditional healthcare settings. In many parts of Africa, digital education has been introduced as a way of expanding education prospects for many. Initiatives like these are spearheaded by international groups such as the Digital Opportunity Trust (DOT) working with youths, governments, and organizations, where they encourage the development of digital skills for young innovators. In addition, through initiatives such as \#EdTech, DOT along with educational institutions foster the digital literacy of teachers and use local content to support digital knowledge of students (Heaphy 2017). This is also seen as a way of introducing school-attending populations to technologies at an early age. Further, digital technologies such as Twitter have enabled the public to express public opinion, pass commentary and generally endeavor to hold politicians to account. Nyabola (2018) captures this phenomenon in her observation of how the people of Kenya have been able to use digital tech- ogy entities and foreign investors, that have their own values and terms and conditions, raises ethical concerns around the aspect of power and what this might mean for the digital transformation of the Global South. Power becomes concentrated in a few hands, as is the case in relation to the ownership of digital platforms as well as China's substantial investment. Hence, there is a danger that a culture of dependency on the benefactors and investors of these digital technologies will arise and increase rather than decrease inequalities. Certainly, there is already a dependency on tech giants, as their products are being used on a daily basis, which intensifies the companies' power over their users (Moore 2016). Similar to the tech giants' power to control access, national governments can obscure access by cutting off internet services in a country, thereby exerting control over the users. The governments of Sudan, the Democratic Republic of Congo, Gabon and Zimbabwe (Fleischmann and Stefanello 2019) have done so in the past.

\section{Assessing the concerns}

The role of technology service providers and countries investing in technological developments in the Global South cannot be overemphasized. Koskinen et al. (2018) state that digital services are enabled by digital platforms mainly from the Global North, which provide opportunities in areas of employment, social networking, and innovation activities. In particular, they point to three types of digital platforms: transaction, innovation, and integration platforms. Some widely used platforms include social media from corporations such as Facebook, e-commerce from Mercado Libre, the 'gig' economy from Upwork including Airbnb (Koskinen et al. 2018, p. 4). Amazon, eBay, Twitter, LinkedIn and WeChat (Turner 2019), among others, are included on the list of digital platforms. 
Michaels (2018) writes about the extent of the influence of proprietors of digital platforms, which can include "depriving users of due process, equal protection, privacy, and various expressive liberties (while at the same time exposing those users to various harms perpetrated by other citizen-consumers)" (p.2). Moore (2016) argues that because of their near monopoly and global positions in the digital economy, technology giants have significant power, which extends to how civic power might be exercised. According to Moore, this is evident in the provision of communication platforms which enable citizens to communicate, inform, and exercise collective action (2016, p. 22). In essence, this is what Nyabola (2018) alludes to when she discusses how social media such as Twitter has been used by Kenyans to organize, express, and voice their political opinions. Kwet (2019) sees the influence and monopolistic position of technology giants, particularly those originating from the US, as enabling digital colonialism.

He argues that the monopolistic power of technology giants can be seen at the architecture level of the digital ecosystem through their provision of software, hardware, and network connectivity. Due to this, Kwet takes the position that because technology giants have the power to mediate the control of users' digital experiences, that control allows technology giants to have economic domination, imperial control, and propagate global surveillance capitalism (2016, p. 2). Similarly, Thatcher et al. (2015) opine that data colonialism is becoming a reality as digital service providers promise a utopian view of a digital society. Thatcher et al. argue that there exist an asymmetrical power relation between the individuals whose actions generate individual data and those who come to own and profit from big data (2015, p. 3). Zuboff (2019) explains that data generated from human experience as free raw material is used to predict behavioral patterns and subsequently predict products useful for the present and the future, which make surveillance capitalists wealthy. This has implications for the power relations between those able to benefit from this phenomenon through provision
Although Anastácio is right to a degree in terms of how digital inclusion in 'underdeveloped' countries is propagated, it is important to note that it is not only diffused by Western initiatives or technology giants from the Global North, but by countries such as China, Africa's seemingly largest investor (Busse et al. 2016). Haroz (2011) reveals that China has been a key actor in providing new technology and professional training for most of Africa. This has been in the form of machinery, electronic equipment, and high-tech products. Zoo (2018) states that between 2003 and 2013, China has invested around 7\% of the $\$ 100$ billion dollars in the communications area in Africa.

Hence, technology giants from the U.S. and from China are in some competition and race to invest in the Global South, particularly in Africa. Where the U.S. giants such as Amazon use the same expansion strategy in Africa as in the U.S. and in Europe, Hruby (2018) states that Chinese companies such as Alibaba enter into partnerships with existing technology companies to advance their hold on such services like cloud computing, clean energy, and new digital technologies. Suffice it to say, the competition is still between technology giants who are hedging their investments for more influence and power in digital technologies in the Global South. This concentrates power in the hands of a few who come with their own terms and conditions, and their own interests and agendas.

\section{Power as an ethical concern}

In critically looking at the aspects presented above, it becomes evident that power is an aspect that needs to be explored further. First, technology giants and investors in the digital realm can have significant influence in the countries they invest in. In addition, such power is extended to national governments who in some cases have been responsible for Internet shutdowns in Africa. Thus, although the technology giants can still provide services, citizens can be deprived of these services by national gov-

\section{Digital technologies developed by technology giants are value-laden, reflecting the values of the developers.}

and investment in digital technologies on the one hand, and the users who provide the data on the other hand.

In adding to the debate around the aspect of inclusion of the poor to the digital society, Anastácio (2016) aptly captures the concerns around this by arguing that "digital inclusion in "underdeveloped" countries have much to do with who controls the Internet and how the Internet is propagated by Western initiatives" (p. 7).

1 Anastácio uses the term 'underdeveloped' to denote developing countries, which this paper covers as the Global South, particularly Africa. ernments when national governments feel the need to control their citizens' use of social media, for example for political purposes. Digital technologies developed by technology giants are value-laden, reflecting the values of the developers.

These values can be seen in how digital technologies are designed to keep users 'hooked' to the digital platforms they use. For example, this is done through persuasive and motivational techniques, which ensure that users keep going back to a digital platform to network, play games or shop online (Ali et al. 2018). This, as Ali et al. (2018) illustrate, can be about 'scarcity'; 'temporary availability and 'social proof' all designed to have us- 


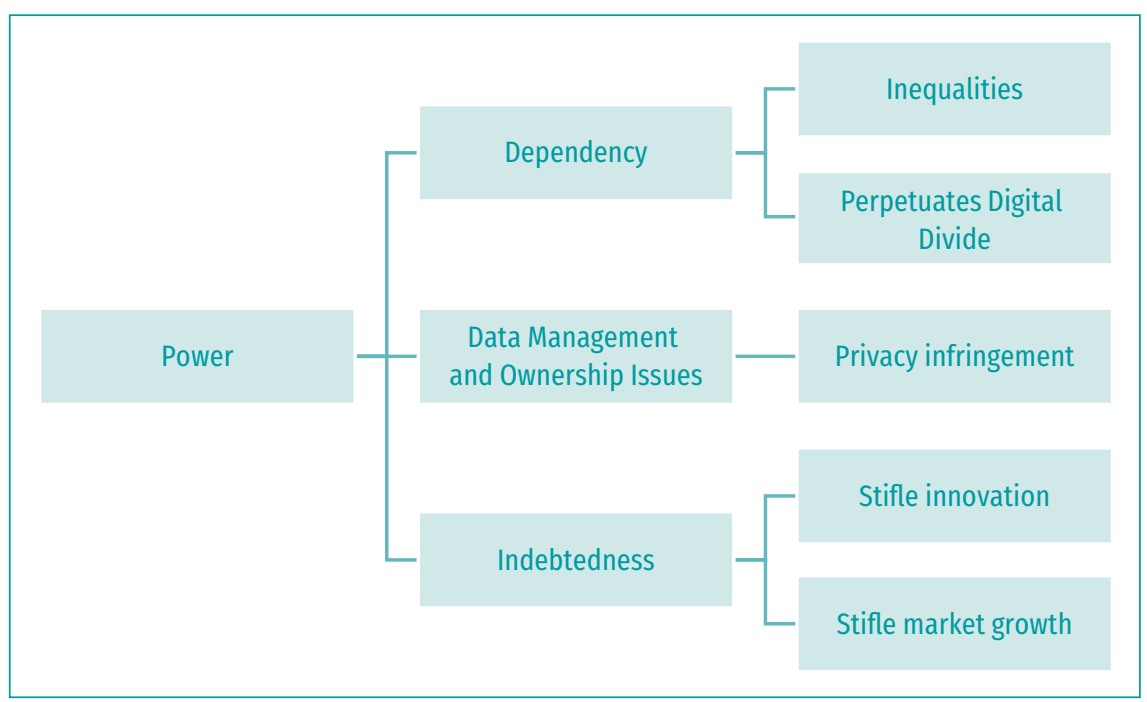

Fig. 1: Illustration of power as a main concern affecting other concerns.

can be disempowering for the users themselves because of the dependency that the users develop on the digital providers. Oxaal and Baden state that this type of power is dichotomous as it involves a relationship of domination and subordination. Power over is also manifested when it comes to the question of who owns the data that is generated on the platforms and how this data is managed. Without adequate policies to protect users, digital proprietors will continue to have power over users' data.

The aspect of power over is not necessarily straightforward. This is because digital platforms offer services that users enjoy and benefit from. Therefore, digital providers and investors could argue that the very nature of the provision of the digital platforms and the digital invest-

ers wanting more and therefore being drawn back to a digital space. The persuasive tactics are a form of power that digital platform proprietors hold over their users. Such power is influential in enabling dependency on the proprietors. This has implications for data control and ownership of said data because data is generally owned by the digital proprietors. The question of who owns data has implications for how that data is protected against possible privacy invasions or how it is used or misused. Consequently, this leads to inequalities and continued digital divides because, if one has no control over their data, one cannot claim to be equal to one who owns the data. As a result, power is at the helm of ethical concerns in the digital transformation of the Global South. Fundamentally, power is an overriding ethical concern with a causal effect on subsequent other ethical concerns (see figure 1).

\section{Conceptualizing power}

\section{Technology giants and power}

Borrowing from concepts of power advanced by Oxaal and Baden (1997), power can be seen in four forms; power over, power to, power with, and power within. From the context of this paper and as a result of the discussion advanced above, power as an ethical concern can be looked at from the perspective of power over digital users by digital platform proprietors, those who invest in digital technologies in the Global South, and national governments. The fact that digital platforms are concentrated in the hands of a few technology giants means that there is an element of power over those who do neither have nor own these digital platforms. Moore (2016) argues that this is especially true when the provision of digital tools is in a monopolistic or oligopolistic manner. This form of power has negative connotations due to the fact that having power over digital users ments taking place in the Global South ensure that the Global South is able to realize its digital transformation. As such, the provision of digital platforms or the investments that enable digital transformation could be argued as giving power to, rather than having power over the Global South. For instance, the provision of the digital technologies has meant that users in the Global South had power to communicate and to innovate. National governments had the ability to provide e-government services to their citizens. Thus, the Global South has the power to solve some of its problems through, for example, the ability to use mobile phones particularly in hard to reach areas or for citizens to harness the power of social media to be able to hold politicians to account.

\section{National Governments and Power}

While citizens have had the power to hold politicians to account as suggested in the previous section, some governments have exercised power over their citizens by denying them the power to use the offered technologies. This has been due to governments' desire to control and stifle their citizens' views, when these have been politically too critical and have used platforms like Twitter. This illustrates how national states can have power over their citizens and their citizens' use of digital platforms.

Given the fact that there is no Facebook or Google originating in the Global South, and given that countries from the Global South are still dependent on more 'developed' countries, the element of dependency on the benefactors perpetuates the power over the recipients of the digital technologies. This dependency (power over) drives countries like Kenya, Rwanda, and South Africa to adopt innovation strategies so that they are no longer that dependent. Kenya for instance has a 2030 vision, which has put the use of technology at the heart of its economy. Rwanda's 2020 vision has enabled a number of initiatives including a digital ambassador's program for its youth. 
Although these countries are technology beacons of Africa, Swart (2011) argues that for many other countries in Africa, there is an element of "use, don't own" due to a lack of security, poor governance, and poor internal continental relations which can stifle innovative use of technologies. A glimpse of how such stifling can manifest itself is in the introduction of tax on popular over the- top services like voice over internet protocol (VoIP) (which includes WhatsApp, an enormously popular digital medium for many in Africa), instant messaging, and social media websites in countries like Zambia, Benin, Uganda, and Tanzania (Alliance for Affordable Internet 2018, p. 17). This has implications for users of these services who would like to use these tech- point of view of the digital transformation of the Global South, power does not only mean domination, but that it can be shared responsibly through the promotion of power with, power to as well as power within digital technology users. Power with is about all stakeholders working towards a common purpose or a common understanding to achieve collective goals. For example, technology giants or national governments can work together with citizens towards developing robust policies around ensuring citizens privacy. That way, power with is exercised collectively for all and with all stakeholders.

Arguably, the discussion thus far has shown that the concept of power can be complex and contestable. On the one hand, us-

\section{The ability to make decisions on how users choose to use digital technologies gives them the opportunity to improve their lives.}

nologies in an innovative way. The fact that they are expected to pay taxes for using these technologies may prove a prohibiting factor in as far as costs are concerned. In addition, such taxes raise questions of state surveillance, which can have personal and political implications on freedom of expression. Recently, the Zimbabwean government shut down the Internet as a measure to suppress protests over fuel hikes (BBC 2019).

\section{Technology Investors and Power}

There is a failure on the part of some countries in the Global South to foster innovation, which leaves them dependent on technology giants or investors such as China. The 'use, don't own' syndrome may mean that countries will not have what is necessary to implement market policies that are favorable to foster an African Facebook, an African Google or an African Alibaba. For instance, as Chinese investment mainly takes the form of loans for infrastructure development (Davis 2018), which is then mainly done by Chinese companies, there may be little encouragement (by foreign players) for innovation at the local level. This can manifest itself in, for example, unequal power relations and a cycle of dependency on the part of the recipient of the investment. Sharkey and Okoroafo (2010) contest that Chinese investment has certain downsides such as the negative impact on local trade and commerce in addition to realizing little benefit if any for African labor. This, then, has implications for how locals are able to innovate and to what extent the technological innovation is fostered.

From the three sections covering technology giants and power; national governments and power; and technology investors and power, it can be noted that in certain instances technology giants, national governments as well as Chinese investors are in a position to exercise power over citizens' ability to be able to effectively use digital technologies. However, from the ers have the power to use digital technologies, but on the other hand, proprietors of digital technologies and national governments have power over their (users') data, which can result in privacy violations. The aspect of having enabling power to means that users of digital technologies are able to use digital technologies to their advantage. For example, they are able to use VoIP digital technologies such as WhatsApp, which can bring many added advantages to their lives. The ability to make decisions on how users choose to use these digital technologies gives them the opportunity to better their lives. As such, the fact that there is an opportunity for them to decide how and whether they use the digital technologies implies that there is power within them. This is an important step towards achieving autonomy and empowerment. However, it is clear that much hinges on other forces for that autonomy and for that empowerment to be truly transformative.

\section{Conclusion}

This paper has explored the digital transformation of the Global South, especially with respect to African countries. Power has been seen as the dominant ethical concern with a causal effect on other concerns such as dependency, data management and ownership, privacy, digital divide, indebtedness, and innovation stifling. In view of its dominant factor, power has been conceptualized as power over, essentially highlighting this dominance. However, the concepts of power with, power to and power within illustrate that digital users do experience some level of empowerment in their use of the technologies in terms of their ability to communicate and express themselves and their views, political or otherwise. However, there is always the danger of platform owners disabling citizens' use of the technology, or national gov- 
ernments disrupting or shutting down the internet, which can deny users' access to the digital platforms. Such potentialities perpetuate power over digital users. As the digital transformation in the Global South gains momentum, the aspect of power over will therefore continue to play a role.

\section{References}

Ali, Raian; Arden-Close, Emily; McAlaney, John (2018): Digital addiction. How technology keeps us hooked. Available online at http://theconversation.com/ digital-addiction-how-technology-keeps-us-hooked-97499, last accessed on 16. 05.2019.

Alliance for Affordable Internet (2018): 2018 affordability report. Available at http://1e8q3q16vyc81g8l3h3md6q555e-wpengine.netdna-ssl.com/wp-content/ uploads/2018/10/A4AI-2018-Affordability-Report.pdf, last accessed on 16. 05.2019.

Anastácio, Kimberly (2016): A view from the cheap seats. Internet and colonialism. GigaNet:. In: SSRN Electronic Journal, n. p. DOI; 10.2139/ssrn.2909369.

BBC - British Broadcasting Corporation (2019): Zimbabwe blocks Facebook, WhatsApp and Twitter amid crackdown. Available online at https://www.bbc.com/news/world-africa-46917259, last accessed on 16. 05.2019.

Busse, Matthias; Erdogan, Ceren; Mühlen, Henning (2016): China's impact on Africa. The role of trade, FDI and aid. In: Kyklos 69 (2), pp. 228-262. Darwell, Stephen (ed.) (2008): Deontology. Malden, MA: Wiley-Blackwell. Davis, Matt (2018): How China is transforming Africa into the next 'factory of the world'. Available online at https://bigthink.com/matt-davis/chinasgrowing-influence-in-africa, last accessed on 24. 05. 2019

Fleischmann, Anne; Stefanello, Viola (2019) African governments use internet shutdowns to silence opposition more and more: What can people do? Available online at https://www.euronews.com/2019/01/26/africangovernments-use-internet-shutdowns-to-silence-opposition-more-andmore-what-can-pe, last accessed on 16.05.2019.

Gigler, Björn (2015): Development as freedom in a digital age. Washington, DC: World Bank.

Haroz, David (2011): China in Africa. Symbiosis or exploitation? In: The Fletcher Forum of World Affairs. 35 (2), pp. 65-88.

Heaphy, Emily (2017): Reducing the digital divide in East Africa. Spotlight on digital literacy and innovation. Available online at https://www.gsma.com/mobilefordevelopment/programme/connectedsociety/reducing-divide-digital-literacy-innovators-east-africa/, last accessed on 16. 05.2019.

Hruby, Audrey (2018): Clash of the US and Chinese tech giants in Africa. Available online at https://www.ft.com/content/ff7941a0-b02d-11e8-99ca68cf89602132, last accessed on 16. 05.2019.

Hursthouse, Rosalind; Pettigrove, Glen (2018): Virtue ethics. Available online at https://plato.stanford.edu/entries/ethics-virtue/, last accessed on 16. 05.2019

ITU - International Telecommunication Union (2010): World telecommunication/ ICT development report 2010. Monitoring the WSIS targets. A mid-term review. Geneva: International Telecommunication Union.

ITU (2018): Measuring the information society report volume 12018. Geneva: International Telecommunication Union.

Koskinen, Kari; Bonina, Carla; Eaton, Ben (2018): Development implications of digital economies. Digital platforms in the Global South. Foundations and research agenda. In: Centre for Development Informatics, Global Development Institute, SEED.

Kwet, Michael (2019): Digital colonialism. US empire and the new imperialism in the Global South. Race \& Class 60 (4), pp. 3-26.

Michaels, Jon (2018): Tech Giants at the crossroads. A modest proposal. Available online at https://www.lawfareblog.com/tech-giants-crossroads-modestproposal, last accessed 16. 05.2019.

Moore, Martin (2016): Tech giants and civic power. Centre for the Study of Media, Communication and Power. The Policy Institute at Kings College London.

Moyo, Admire (2017): Gauteng pilots robotic dispensers for chronic patients. Available online at https://www.itweb.co.za/content/XlwrKx73AbBqmg10, last accessed on 16.05.2019.

Nyabola, Nanjala (2018): Digital democracy, analogue politics. How the internet era is transforming politics in Kenya. London: Zed Books.

Oxaal, Zoe; Baden, Sally (1997): Gender and empowerment. Definitions, approaches and implications for policy. Brighton: BRIDGE.

Sharkey, Thomas; Okoroafo, Sam (2010): The impact of Chinese investment in Africa. In: International Journal of Business and Management 5 (9), pp. 1-7

Swart, Dirk (2011): Africa's technology futures. Three scenarios. Boston: Boston University Press.

Thatcher, Jim; O'Sullivan, David; Mahmoudi, Dillon (2015): Data colonialism through accumulation by dispossession. New metaphors for daily data. Available online at https://ssrn.com/abstract=2709498, last accessed on 16.05.2019.

Turner, Jamie (2019): 2019: Top 57 social media platforms every executive should know (Updated). Available online at https://60secondmarketer.com/ blog/2010/04/09/top-52-social-media-platforms-2/, last accessed on 16.05.2019.

World Bank (2018): Information and Communications for Development: DataDriven Development. Washington, DC: World Bank Group.

Wu, Jinsong; Guo, Song; Huang, Huawei; Liu, William; Xiang, Yong (2018): Information and communications technologies for sustainable development goals. State of-the-art, needs and perspectives. In: IEEE Communications Surveys \& Tutorials, 20 (3), pp. 2389-2406. DOI: 10.1109/COMST.2018.2812301.

Zoo, Stephany (2018) Here's why the tech sector could be the next target for Chinese investment in Africa. Available online at https://www.weforum.org/ agenda/2018/09/china-africa-tech/, last accessed on 16.05.2019.

Zuboff, Shoshana (2019): The age of surveillance capitalism. The fight for a human future at the new frontier of power. New York: Public Affairs.

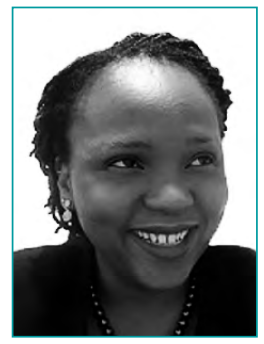

\section{DR. KUTOMA WAKUNUMA}

is a Senior Lecturer and Researcher at De Montfort University where she has worked since 2009. Her main interest is in understanding the social and ethical aspects of ICTs on modern society. Her research areas include Emerging Technologies, Ethics, Gender, Civil Society Organisations, Monitoring \& Evaluation and Responsible Research and Innovation. 